\title{
Rememorando os Filhos de Onontio: Richard White, The Middle Ground e a escrita da história da América do Norte colonial
}

\section{Remembering the Children of Onontio: Richard White, The Middle Ground and the writing of the history of Colonial North America}

Resumo: Publicado em 1991, o livro The Middle Ground, do historiador norte-americano Richard White, ajudou a revolucionar a escrita da história da América do Norte colonial, com uma perspectiva que enfatizava a ação indígena e a formação de um processo de acomodações e compromissos na região dos Grandes Lagos. Com isso, White conseguiu criar uma narrativa que fugia dos simples tropos de “assimilação" e “conquista”, fornecendo, assim, uma história preocupada com a recuperação do Outro enquanto ator histórico legítimo.

Palavras-chave: Historiografia norte-americana. Richard White. Middle ground.

\begin{abstract}
Published in 1991, The Middle Ground, a book written by American historian Richard White, helped to bring about a revolution in the writings of Colonial North American History, with a perspective that gave emphasis to Indian exploits and the formation of a process of accords and commitments throughout the Great Lakes region. White managed to create a narrative that moved away from such terms as "assimilation" and "conquest”, thus providing an account concerned with recovering the Other as a legitimate historical protagonist.
\end{abstract}

Keywords: American historiography. Richard White. middle ground.

\footnotetext{
* Doutor em História pela Universidade Federal do Rio Grande do Sul. Este artigo recupera algumas das considerações feitas em minha tese de doutorado. Trabalho realizado com o auxílio do CNPq, no Brasil, e da CAPES, nos Estados Unidos. Contatos: arthurlavila@gmail.com
} 
Rememorando os Filhos de Onontio: Richard White, The Middle Ground e a escrita da história da América do Norte colonial

\section{Introdução}

Em 1813, durante a guerra entre norte-americanos e ingleses, o líder indígena Tecumseh pereceu na batalha de Thames. Um guerreiro shawnee, nativo da região dos Grandes Lagos da América do Norte, Tecumseh havia se aliado aos britânicos, com o intuito de tentar conter a voracidade territorial da jovem república dos Estados Unidos. Seu esforço foi em vão. Derrotado pelos estadunidenses e abandonado pelos súditos do Rei Jorge III, Tecumseh caiu no campo de batalha, e seus sonhos de uma última grande confederação indígena morreram com ele. A partir deste momento, a importância política dos algonquinos, grupo étnico-linguístico ao qual pertenciam os shawnees, outrora poderosos como agentes no jogo entre impérios coloniais, diminuiu consideravelmente. Com isso, estava aberto caminho para a expansão norte-americana. Ao menos no Nordeste e nos Grandes Lagos, os nativos não mais conseguiriam se impor política e militarmente diante do Império inglês e dos Estados Unidos da América. O middle ground chegara ao fim. ${ }^{1}$

Este é o epílogo da história contada por Richard White (1991) em sua obra magna, The Middle Ground. Nela, White, um eminente historiador ligado à História Ambiental, à História Indígena e à História do Oeste dos Estados Unidos, narrava a criação de um espaço de acomodação e de compromissos entre colonizadores e colonizados nos Grandes Lagos da América do Norte, no período colonial. Considerado como um “terremoto historiográfico” (BARKSDALE, 2007, p. 9696), pela sua importância para a área de História Colonial norte-americana ${ }^{2}$, o livro foi vencedor de dois prêmios importantes no campo da História norte-americana: o Prêmio Albert J. Beveridge e o Prêmio Francis Parkman, o primeiro fornecido pela American Historical Association para a melhor publicação em língua inglesa sobre a América do Norte, e o segundo dado pela Society of American Historians aos textos historiográficos com alto valor literário. Além disso, em 1992, The Middle Ground foi um dos finalistas do prestigioso Prêmio Pulitzer em História. ${ }^{3}$ Além destas láureas, a obra foi merecedora dos mais diversos elogios por seus pares. Ainda em 1992, três das principais revistas acadêmicas norte-americanas publicaram resenhas em que historiadores consagrados louvavam a chegada de tal trabalho, apontando, principalmente, a originalidade do tema e da forma do livro. Para todos eles, The Middle Ground representou, ao menos nos Estados Unidos, uma ampliação das possibilidades de se tramar a história do passado colonial da América do Norte (BERKHOFER, 1992, p.1134-1135; CALLOWAY, 1992, p.447-452; MANCALL, 1992, p.15871588). ${ }^{4}$ O que, contudo, havia de tão inspirador no texto de White? Como ele, segundo seus pares, revolucionara a historiografia da América colonial? 
Considerando-se estas indagações, a proposta deste artigo é analisar, brevemente, a reescrita da história da América do Norte colonial proposta por White em The Middle Ground, enfatizando sua intenção de resgatar a agency indígena e recuperar sua historicidade, não como o Outro silenciado e domesticado da historiografia tradicional, mas como parte essencial do processo histórico que gerou a moderna América setentrional. Além disso, buscaremos ressaltar as "políticas da história” de The Middle Ground, isto é, qual o passado que White buscava (re)criar para a América conturbada de fins do século XX.

À vista do exposto, pretendemos analisar o livro a partir de uma história da historiografia, isto é, a partir de uma postura que considera nossa disciplina como sendo fundamentalmente histórica (GUIMARÃES, 2007, p.70). Sob este ângulo, a tal postura equivaleria ao estabelecimento de uma perspectiva crítica sobre o passado, o presente e os nossos usos contemporâneos do passado, abrindo caminho para uma historiografia mais autoreflexiva e ciente de seus limites e possibilidades.

O artigo está dividido em três partes, além da presente introdução. No primeiro ponto, recuperamos a biografia intelectual de White, ressaltando sua ligação com dois importantes momentos historiográficos norte-americanos, a “New Indian History” (NIH) e a "New Western History” 5 (NWH). Na parte seguinte, analisamos a escrita de The Middle Ground, principalmente no que tange ao conceito de middle ground que opera em todo o livro. Finalmente, no terceiro ponto, examinamos o subtexto político do magnum opus de White e o horizonte de expectativa que o historiador procura abrir com seu texto.

\section{Os lugares de Richard White}

Filho de um judeu russo e de uma imigrante irlandesa, Richard White nasceu na Califórnia, em 1947, graduando-se em História pela Universidade da Califórnia, Santa Cruz, em 1969. Tendo obtido o título de doutor em 1975, pela Universidade do Estado de Washington, White lecionou nas universidades de Utah e Michigan, antes de assumir um posto na Universidade do Estado de Washington. Em 1998, foi contratado pela prestigiosa Universidade Stanford, onde atualmente é titular da Cadeira Margaret Byrne de História dos Estados Unidos.

Sua tese de doutorado foi transformada em livro e lançada, em 1979, sob o título Land Use, Environment and Social Change: the shaping of Island County. Esta obra já apontava o caminho futuro de White, na medida em que fundia duas de suas maiores preocupações: a história dos indígenas norte-americanos e as relações entre os homens e a natureza. O livro pretendia ser uma “história total” de uma pequena região no litoral do Estado de Washington, no noroeste dos Estados 
Rememorando os Filhos de Onontio: Richard White, The Middle Ground e a escrita da história da América do Norte colonial

Unidos, tendo por foco a história das mudanças causadas no meio-ambiente pelos índios e pelos brancos e as consequências destas alterações para as pessoas que as realizaram, num período que se estendia do século XIII ao XX (WHITE, 1979, p.5). O intuito de Land Use... era justamente desmistificar a ideia de uma comunhão perfeita entre indígenas e meio-ambiente, demonstrando as profundas modificações da natureza realizadas pelas sociedades nativas, ao mesmo tempo em que as diferenciava do tipo de modificação, muito mais destrutiva, causadas pelos brancos no mundo natural.

Já seu segundo livro, Roots of Dependency, publicado em 1983, possuía uma finalidade política mais clara (e que, de certa forma, será replicada em The Middle Ground): desvelar as raízes da dependência de dois grupos indígenas diferentes do Oeste norte-americano, os pawnees e os navajos, e um do Sul, os choctaws. Utilizando-se da "teoria da dependência”, como elaborada por Immanuel Wallerstein e pelo brasileiro Theotônio dos Santos, como marco teórico fundamental, a segunda obra de White tentava explicar a passagem destes grupos de um estado autosubsistente a um de dependência em relação aos brancos. Ao narrar a dissolução dos mundos de choctaws, pawnees e navajos, White enquadrou estas mudanças sociais profundas no âmbito da expansão do capitalismo moderno e da incorporação das sociedades nativas ao sistema-mundo capitalista. De acordo com o historiador:

The collapse of their subsistence systems and their integration into world markets brought increasing reliance on the capitalist core, lack of economic choice and profound social and polítical changes within their societies ${ }^{6}$ (WHITE, 1983, p. XVIII-XIX).

A moral desta história, por assim dizer, era desvendar a imbricação entre a ação humana na natureza e as mudanças sociais causadas por esta mesma ação. No caso de Roots of Dependency, a intervenção dos euro-americanos no mundo natural desestruturou os modos de subsistência indígenas a partir da introdução da lógica de mercado inerente ao modo de produção capitalista. Esta lógica acarretou o enfraquecimento e, finalmente, a completa desestruturação destas sociedades. Para White (1983, p.XIV-XV), portanto, a conquista pelo mercado muitas vezes antecedeu e abriu caminho para a subjugação militar dos ameríndios.

Com estes dois livros, ainda hoje reconhecidos como contribuições importantes para a História Indígena estadunidense (MILNER et al, 2002), White afirmou-se como autoridade da chamada New Indian History. Este “movimento” surgiu, como seu próprio nome indica, como resposta à “antiga história indígena” que, segundo o próprio White (1991, p.XI), era apenas a história da política indigenista dos brancos em diferentes momentos do passado dos Estados 
Unidos. Nesta historiografia, os indígenas eram agentes passivos que só respondiam aos estímulos dos brancos. Suas ações só poderiam ser compreendidas, segundo esta visão, a partir de suas relações com o mundo dos brancos. Os interesses dos nativos eram, assim, subestimados, minimizados ou, em alguns casos mais extremos, descartados por estes historiadores (EDMUNDS, 1995, p.735-738).

As origens da NIH podem ser encontradas, segundo um de seus maiores proponentes (BERKHOFER, 1971, p.357-359), na agitação social dos anos 1960, com o conseqüente surgimento de diversos grupos políticos indígenas, como o Movimento do Índio Americano e o Red Power, que, inspirados pelo sucesso do Movimento pelos Direitos Civis dos afro-americanos, buscavam lutar pelos direitos civis dos próprios indígenas. ${ }^{7}$ Opondo-se à antiga historiografia, a NIH buscava recuperar a agency nativa, entendendo a ação indígena em seus próprios termos e não somente em relação aos brancos. Segundo Berkhofer (1971, p.364), estas novas histórias almejavam representar os indígenas como indivíduos lidando criativamente com as diferentes situações históricas em que se encontravam. Em outras palavras, como atores legítimos do processo histórico.

Apesar de determinadas oposições sociais e institucionais (EDMUNDS, 2008, p.11-12), a $\mathrm{NIH}$ logrou ser bem sucedida em suas intenções originais, principalmente no que tange à incorporação dos nativos à história norte-americana. ${ }^{8}$ Segundo William T. Hagan (1997, p.29-42), era grande a quantidade de trabalhos monográficos sendo produzidos no campo nas décadas de 1970 e 1980. Ao afirmar que a presença nativa fora uma constante durante todo o século XX, a despeito da brutalidade aos quais os indígenas foram submetidos e das proposições da inevitabilidade de sua assimilação à sociedade branca, a NIH contribuiu para aquele processo de democratização da historiografia norte-americana, com a introdução de novas vozes, novas perspectivas e novos métodos, ocorrido a partir da década de 1970 (WEINSTEIN, 2004, p.186). Se a NIH não se tornou tão visível, por exemplo, como as histórias de gênero e de outras minorias sociais e raciais, como lembra Edmunds (2008, p.14-15), que sua contribuição tenha sido menor que as destes campos.

Por outro lado, o surgimento da NIH andou de mãos dadas com o revisionismo interno de outro campo da História norte-americana, a Western History, dedicada ao estudo da fronteira e do Oeste estadunidense. Institucionalizada à imagem e semelhança de seu pai fundador, Frederick Jackson Turner, a Western History teve por principal pilar, durante boa parte do século XX, a chamada "frontier thesis". Primeiramente imaginada por Turner, e depois refigurada por uma série de autores, esta tese postulava que o avanço das fronteiras ocidentais norte-americanas havia sido o motor do desenvolvimento histórico dos Estados Unidos. Em seu clássico ensaio de 1893, Turner 
Rememorando os Filhos de Onontio: Richard White, The Middle Ground e a escrita da história da América do Norte colonial

(1996, p.1), escreveu que a existência de uma ampla área de "terras livres” a Oeste havia sido o fator mais significativo da história estadunidense. A presença desta fronteira, conceituada como o ponto de encontro entre a civilização e a barbárie (TURNER, 1996, p.1-2), transformara os Estados Unidos em uma nação continental, economicamente rica e politicamente democrática - ao contrário do que ocorria no “decadente” Velho Mundo.

Originalmente, a tese de Turner, repleta de nuances que não podem ser esmiuçadas neste breve espaço, não era insensível à presença indígena. Turner construiu o cenário fronteiriço como um espaço de atuação e interação, tanto para os brancos como para os indígenas. Em outras palavras: a fronteira podia ser entendida como uma zona de interação (social, econômica e cultural) entre estes dois grupos. Um não existia sem o outro (KLEIN, 1997, p. 195). Não foi assim, contudo, que seus seguidores mais importantes entenderam o conceito. Para eles, a "fronteira” era a dura divisão entre dois mundos, não uma área de interatividade. De um lado, estava a natureza e suas “crianças”, os índios (e, em menor grau, os mestiços, franceses e espanhóis), e de outro, os norteamericanos de origem anglo-saxônica.

Nos livros de autores como Ray Allen Billington e Frederick Paxson, entre outros, a antiga definição turneriana é transformada em uma divisão absoluta entre “civilização” e “natureza”, sem espaço para as nuances e ambiguidades, e para a originalidade linguística, de Turner. O “outro lado”, o lado "selvagem”, essencial na definição de Turner, desaparece completamente (AVILA, 2010, p.38-40).

O peso da frontier thesis na Western History significou a naturalização de uma versão da história americana em que os índios eram somente obstáculos ao progresso norte-americano. Embora alguns western historians importantes, como Wilbur Jacobs e Francis Jennings, tivessem sido pioneiros no estudo da história indígena, o campo, em geral, foi bastante negligente com os nativos até, pelo menos, a década de 1970. Quando este modelo tradicional de se fazer e escrever a história do Oeste e da fronteira entrou em crise, uma nova geração de historiadores buscou reescrever a Western History a partir de outras perspectivas que não a da frontier thesis. Richard White estava entre eles, junto a outros nomes importantes, como Patrícia Limerick e Donald Worster.

White participou ativamente da chamada “New Western History”, movimento iniciado na década de 1980 e que buscava condensar as revisões e críticas da Western History pós-1970. Ainda que a NWH não fosse algo homogêneo, e que várias de suas perspectivas não se sustentassem diante de um escrutínio crítico mais amplo ${ }^{9}$, ela teve o mérito de abrir caminho para uma profunda renovação do campo. Neste caso, White talvez tenha sido um dos historiadores mais importantes 
deste processo. A partir de fins da década de 1970, White participou desta reescrita coletiva da história do Oeste, a partir de temas como os conflitos interíndigenas do século XVIII (WHITE, 1978), enfatizando as dinâmicas internas destas sociedades, e as relações raciais no Oeste do século XIX (WHITE, 1986), em que desafiava a ideia de um país birracial dividido entre brancos e negros e incluía asiáticos, indígenas e mestiços num caleidoscópio cultural e social bastante tenso e, não raro, mais violento do que os conflitos raciais do Sul.

Suas proposições teóricas mais amplas sobre a história do Oeste e da fronteira podem ser encontradas em um pequeno, mas contundente, artigo de 1989 (WHITE, 1989, p.27-29), em que White afirmava ser necessário olhar para as margens do processo histórico, com o intuito de transformá-las em centros. Não bastava somente a mudança de conteúdo, mas uma mudança nos termos em que se narrava a história do Oeste e da fronteira. Se a antiga historiografia havia celebrado a conquista do Oeste em termos triunfalistas e glorificadores dos feitos dos anglosaxônicos da América do Norte, a nova tinha o dever de chamar atenção para aqueles aspectos “irônicos” da história da região, isto é, o descompasso entre as intenções das pessoas e o resultado de suas ações. A reescrita da história regional nestes termos serviria, assim, para conscientizar os norte-americanos dos limites e consequências inerentes à ação humana no país e no mundo (WHITE, 1989, p. 32).

Foi nos interstícios da NIH e da NWH que White conduziu uma parte de sua obra (a outra, como já foi dito, refere-se à História Ambiental, tema do qual não trataremos neste artigo). Recuperando as complexidades das relações entre grupos humanos e destes com seu meio-ambiente imediato, e mantendo uma postura sempre autoconsciente quanto ao caráter escrito e contingente do conhecimento histórico (WHITE, 1998), White constituiu um corpus historiográfico que, já em fins da década de 1980, o haviam alçado à condição de uma das maiores autoridades nos campos acima mencionados. Em parte por causa do capital simbólico adquirido a partir das posições de seu autor, e em parte por causa das discussões que originou, The Middle Ground, rapidamente, adquiriu suma importância para a historiografia norte-americana. Sintetizando algumas de suas posições anteriores e introduzindo algumas nuances, White produziu, assim, uma importante e criativa releitura do passado colonial da América do Norte.

\section{Escrevendo o middle ground}


Rememorando os Filhos de Onontio: Richard White, The Middle Ground e a escrita da história da América do Norte colonial

White começa sua obra mais famosa com uma frase que resume bem a antiga historiografia sobre as relações entre brancos e indígenas: "the history of Indian-white relations has not usually produced complex stories” ${ }^{\prime 0}$ (1991, p.ix). Como uma constante tempestade, o mar encontra as rochas, até dissolvê-las completamente ou deixar somente alguns poucos traços de sua existência. Esta era, para White (1991, p.ix), a metáfora organizadora das velhas narrativas: ou se enfatizava a conquista completa e a desaparição dos nativos, ou se afirmava sua persistência cultural estática, embora apartada do mundo social mais amplo. Em ambos os casos, as histórias eram relativamente simples, celebrando o triunfo branco ou lamentando a inevitável tragédia indígena. The Middle Ground buscava, assim, segundo as palavras de seu autor, complicar estas narrativas:

The meeting of sea and continent, like the meeting of whites and Indians, creates as well as destroys. Contact was not a battle of primal forces in which only one could survive. Something new could appear ${ }^{11}$ (WHITE, 1991, p. IX).

Era esta a conformação desta nova situação que White buscava narrar no livro. Para se contar a história da região dos Grandes Lagos do período colonial, os simples topoi de conquista ou assimilação não bastavam ${ }^{12}$. Era preciso uma narrativa menos linear e mais atenta, principalmente, às contingências peculiares do chamado pays d'en haut ${ }^{13}$. Para descrever esta situação, portanto, White lança mão do conceito que estrutura todo o texto e dá título ao livro: middle ground. O contexto do pays d'en haut era peculiar justamente pela incapacidade dos franceses (e, mais tarde, dos ingleses) em conseguir impor completamente seu projeto colonizador. Por outro lado, os algonquinos, o principal grupo étnico-linguistico nativo da região ${ }^{14}$, também não possuíam poderio suficiente para se contrapor militarmente aos europeus. Desta forma, ambos os lados da contenda tiveram que construir um mundo de inteligibilidade mútua, com a intenção principal de defender seus próprios interesses mais amplos. Incapazes de conquistar completamente os algonquinos, os franceses necessitavam deles para o sucesso de seu império colonial, constantemente ameaçado pela pressão das colônias inglesas, mais ricas e povoadas, ao sul. Sem condições de repelir os invasores, os algonquinos precisavam chegar a um acordo com os europeus, para poderem preservar sua própria soberania e interesses. Chega-se, assim, à condição do middle ground. Esse, nos diz White, era:

The place in between cultures, peoples, and in between empires and the nonstate world of villages. It is a place where many of the North American subjects and allies of empires lived. It is the area between the historical foreground of European invasion and occupation and the background of Indian defeat and retreat ${ }^{15}$ (WHITE, 1991, p. X). 
Com esta conceitualização, White diferencia, como percebeu Phillip Deloria (2006), middle ground de "fronteira”, não reduzindo o primeiro à segunda. Sob este aspecto, o middle ground exige uma situação fronteiriça para a sua emergência, mas nem todas as situações fronteiriças resultam em tal meio termo. Como demonstrado por diversos autores, em alguns lugares da América do Norte, o middle ground prosperou; em outros, não (DUVALL, 2004; BARR, 2006; TAYLOR, 2006);. O próprio historiador afirmou recentemente:

I was fairly specific about the elements that were necessary for the construction of such a space: a rough balance of power, mutual need or a desire for what the other possesses, and an inability by either side to commandeer enough force to compel the other to change. Force and violence are hardly foreign to the process of creating and maintaining a middle ground, but the critical element is mediation ${ }^{16}$ (WHITE, 2006, p. 10).

Por meio desta sutil, mas profunda diferenciação entre "fronteira” e o middle ground, White conseguiu enquadrar sua história na metanarrativa mais ampla da expansão das fronteiras americanas, sem, contudo, submeter-se a uma visão linear deste processo, escapando das antigas histórias de conquista ou assimilação (DELORIA, 2006, p. 21).

O conceito de middle ground opera, também, num nível metafórico bastante importante para a própria estrutura narrativa do livro, já que aponta tanto para um espaço, o pays d'en haut, quanto para um processo, a formação de compromissos e acomodações. Como percebeu Catherine Desbarats (2006, p.90), isto possibilitou a exploração das inúmeras possibilidades positivas existentes, em vários momentos e em várias escalas, de criação de novas práticas culturais em cenários multiculturais, ao mesmo tempo em que enfatizou a presença contínua de forças destrutivas - de guerras e epidemias a interesses imperiais mais amplos - presentes neste processo. Desta forma, o livro não é somente uma narrativa de redenção de conflitos antagônicos, mas um reconhecimento da capacidade humana de encontrar certos compromissos em meio ao caos e à violência das situações de convivência forçada de diferentes grupos humanos.

O middle ground foi um espaço onde o hibridismo e a acomodação cultural tornaram-se a regra e não a exceção. Inexiste, portanto, a assimilação completa de um grupo pelo outro; o que ocorre é o surgimento de novas práticas e significados, compartilhados por europeus e indígenas (WHITE, 1991, p. 93-141). Isto não significa, entretanto, a inexistência de conflitos. Pelo contrário, o pays d'en haut não era um Éden perdido de perfeita harmonia humana e não devia ser romantizado: em alguns momentos, era um lugar extremamente violento e terrível - como, aliás, o próprio White (1991, p. 1-49) demonstra em seu primeiro capítulo. Foi justamente esta violência 
Rememorando os Filhos de Onontio: Richard White, The Middle Ground e a escrita da história da América do Norte colonial

primeira, causada pela chegada dos europeus, pelas brutais guerras entre os algonquinos e outros grupos indígenas, e a consequente dissolução do mundo pré-colombiano dos Grandes Lagos, que abriu a possibilidade de constituição do middle ground:

The middle ground grew according to the need of people to find a means, other than force, to gain the cooperation or consent of foreigners. To succeed, those who operated on the middle ground had, of necessity, to attempt to understand the world and the reasoning of others and to assimilate enough of that reasoning to put it to their own purposes ${ }^{17}$ (WHITE, 1991, p. 52).

Esta necessidade, intrínseca ao projeto colonial da Inglaterra e da França, acabou criando uma ampla possibilidade de ação por parte dos nativos. Para White, isto significa uma profusão de fontes e a oportunidade de trazer estes nativos para o centro da história colonial dos Estados Unidos e do Canadá. Esta centralidade fica mais clara no capítulo em que White narra a estruturação da aliança entre os algonquinos e os franceses. Seu surgimento foi uma decorrência da relação estabelecida entre ambos por meio do comércio de peles: os peaux-rouge forneciam as mercadorias desejadas pelos europeus e, em troca, recebiam presentes e outros bens, incluindo armas de fogo e bebidas alcoólicas. Aqui, contudo, o relacionamento ainda era, por assim dizer, meramente instrumental.

No final do século XVII, entretanto, a preocupação do Império Francês em ocupar efetivamente as terras do pays d'en haut e de protegê-las de seus rivais anglo-saxônicos acabou funcionando para a forja de laços mais profundos entre os nativos e os europeus. Ela operou a partir da lógica do middle ground, ou seja, mediante compromissos mútuos e acomodação entre ambos. Deste modo, o governo colonial não conseguiu transformar os índios em meros súditos, impondolhes suas vontades, mas os incorporou como aliados à sua causa, ainda que nem sempre em pé de igualdade. Os administradores do Canadá reconheciam abertamente a obrigação de manter os algonquinos satisfeitos e efetivamente incorporados à aliança, através da troca de presentes, do fornecimento de suprimentos, da proteção militar contra seus inimigos e da mediação de confrontos no seio das diversas tribos da região ${ }^{18}$ (WHITE, 1991, p.85-90). Em contrapartida, os sauvages, como eram chamados pelos brancos, comprometiam-se em comerciar peles somente com Montreal e em auxiliar Onontio, como chamavam o governador francês, em suas lutas contra os ingleses e outros adversários. Vista sob este ângulo, esta união foi menos uma imposição imperial do que uma condição fundamental para a segurança de franceses e algonquinos (WHITE, 1991, p.142-185).

White chega a estas conclusões a partir de algumas cartas escritas por lideranças algonquinas ao governo colonial e das transcrições de encontros entre os representantes dos nativos 
e os das autoridades europeias. Nesta documentação, são os próprios índios que discutem a conformação do middle ground. A ideia de uma passividade indígena, como vítima ou como simples figurante das ações europeias no continente, é, assim, substituída pelo seu protagonismo, muitas vezes independente das demandas da aliança ${ }^{19}$. Mas, mais do que isso, o discurso nativo também revelava uma grande capacidade de encontrar estratégias que os favorecessem dentro do esquema colonial. A distribuição de presentes, um costume algonquino de retribuição e garantia de lealdade diante de um compromisso firmado, era um exemplo disto. Se por um lado os franceses entregavam mercadorias para os chefes que queriam ver favorecidos nas rivalidades intertribais, por outro, os nativos as utilizavam para garantir a existência de uma ampla rede de fidelidade entre seus líderes. Esta rede não era necessariamente movida pela lógica da aliança, como os europeus a entendiam. Pelo contrário, estes bens eram trocados com a função de assegurar a proeminência de certos grupos sobre outros dentro das aldeias, independente daqueles preferidos pelas autoridades coloniais. Neste caso, a política tribal submetia a política imperial aos seus próprios desígnios, sem que os supostos dominadores pudessem fazer muita coisa a respeito. Isto, contudo, só foi possível por causa da existência de uma elite letrada entre os algonquinos, normalmente educada nas várias missões jesuíticas existentes nos Lagos e de origem mestiça (os chamados métis), que fazia a mediação entre Montreal e os povoados do pays d'en haut. Eles atuavam como agentes do poder colonial, na medida em que ajudavam em seu aparato administrativo e como agentes políticos tribais, já que nem sempre cumpriam as vontades dos brancos quanto à distribuição dos presentes (WHITE, 1991, p.74).

Esta ênfase na agency nativa faz com que a narrativa escape aos problemas que Kerwin Klein (1997, p.230-231) e o próprio White (1998, p.220) identificaram como comuns a algumas obras sobre a história indígena: o da idealização do passado indígena e da sua "retirada” da história. ${ }^{20}$ No primeiro caso, a América pré-colombiana era considerada como um Éden, só corrompido com a chegada dos primeiros europeus. Os nativos eram como Adão e Eva antes da Queda: eles não possuíam pecados e viviam em plena harmonia com a natureza e entre eles mesmos. Esta concepção engendra o segundo ponto, na medida em que o presente é desvalorizado, porque os índios haviam perdido sua “pureza” original, e o futuro é temido, já que, sem forças para resistirem ao avanço da sociedade branca, os remanescentes destes grupos seriam movidos à assimilação completa de modo inevitável. O que ocorre em The Middle Ground é justamente o contrário: os algonquinos são entendidos como tendo uma existência, pré ou pós-contato, complexa, sujeita tanto a momentos de extrema crueldade ou de tocante generosidade. Do mesmo modo, sua história não se move em direção a um futuro necessariamente predeterminado: as Primeiras Nações lutam, perdem, ganham, se acomodam e tentam construir um mundo em que elas ainda poderiam ter 
Rememorando os Filhos de Onontio: Richard White, The Middle Ground e a escrita da história da América do Norte colonial

algum espaço. Os ameríndios não são vítimas passivas, ainda que nobres e puras, do avanço branco; eles resistem ou se adaptam a ele, dependendo das circunstâncias. É evidente que as consequências deste processo foram trágicas para os nativos, mas isto não significa que isto estivesse dado a priori. Eles resistiram, e muito, para impedir tal desfecho.

Ao devolver a este cenário uma complexidade que muitas vezes havia sido minimizada ou negada, White (re)cria uma América do Norte em que as contingências do processo colonizador apontavam para futuros diversos. Um dos exemplos disto é a sua análise da rebelião de Pontiac, chefe algonquino que se revoltou contra os ingleses, após a conquista das colônias francesas pelo Império Britânico ${ }^{21}$. O líder indígena se insurgiu não para impedir a posse destas terras pelos soldados de Jorge III, mas para garantir que o middle ground fosse respeitado pelas novas autoridades coloniais ${ }^{22}$. Em outras palavras, o insurreto e seus seguidores queriam assegurar que $o$ mundo comum construído por europeus e nativos naquela porção do continente americano não seria destruído com esta drástica mudança (WHITE, 1991, p.271-272).

Pontiac não surge como um selvagem sedento por sangue branco, nem como um nobre líder se atirando em uma derradeira tentativa de salvar seu povo da inevitável extinção completa, mas como um astuto estrategista interessado em preservar o middle ground da dissolução. Uma das estratégias utilizadas por White para adquirir este efeito é, principalmente, recuperar as falas de Pontiac e seus companheiros rebeldes, mesmo que as fontes sejam fragmentárias. ${ }^{23}$ Assim, o que vem à tona é um emaranhado de ações, intenções e desejos indígenas, muitos deles pouco ou nada conectados às ações, intenções e desejos dos colonialistas, fossem eles súditos da fleur-de-lis ou da Cruz de São Jorge.

Como relatou White, Pontiac e seus seguidores podiam estar envolvidos diretamente em uma disputa imperial, mas, sob outro ângulo, eles seguiam um caminho que era claramente algonquino, tentando assegurar aos nativos um papel de predominância no pays d'en haut. A sua rebelião acabou sendo esmagada pelos ingleses, mas a insurreição, por si só, acabou forçando os britânicos a encarar a necessidade de se manter uma aliança constante com os indígenas. Neste sentido, e paradoxalmente, a derrota militar não representou um passo em direção à submissão e à assimilação completa das Primeiras Nações, sendo um reajuste de forças no sentido da reafirmação do middle ground. Convencidos do poder militar dos algonquinos, os ingleses acabaram aceitando uma aliança com eles, baseada, como antes, em certos compromissos recíprocos (WHITE, 1991, p, 299-314).

Mas, sem dúvida, o momento mais tocante desta história é justamente quando o middle ground começa a ser lentamente desfeito e o espaço comum entre nativos e europeus começa a ruir. 
O ponto desta ruptura é a Revolução Americana, em 1776, e a subsequente independência dos Estados Unidos. Ainda que a aliança entre britânicos e algonquinos tivesse sido bastante precária, especialmente quando comparada à experiência francesa, ela sem dúvida fora eficiente. Após a emancipação das Treze Colônias, esta política foi abandonada em prol de duas contíguas e muito mais perniciosas, apesar de aparentemente opostas: a do extermínio e a da benevolência. A primeira, obviamente, postulava uma guerra total contra os nativos e era alimentada, principalmente, pelos colonos da fronteira, sequiosos pelas terras indígenas. É aqui que começa, portanto, a triste história de tratados rompidos, expulsões e morticínios, que se tornaria comum no século seguinte.

A política da benevolência foi, contudo, tão nefanda para os algonquinos quanto a primeira. Nesta, o extermínio não era físico, mas cultural, e o middle ground era abandonado em prol de um assimilacionismo bastante radical, que postulava a impossibilidade completa da coexistência entre os dois mundos. Em outras palavras, esta ideologia, que se tornou ainda mais acentuada durante a presidência de Thomas Jefferson (1801-1809) ${ }^{24}$, colaborou decisivamente para a destruição total do middle ground, na medida em que encarava os índios como sendo moral e racialmente inferiores aos europeus. Em sua perspectiva, só restavam duas opções aos nativos: a assimilação à sociedade branca ou o extermínio (WHITE, 1991, p.469-476). É nesse momento da história estadunidense que os índios renascem como o Outro perigoso e ameaçador que ronda a América anglo-saxônica:

Americans invented the Indians and forced the Indians to live with this invention. [...]. Ever since we have seen the history of the colonial and early republican period through that prism of otherness (WHITE, 1991, p. XV). ${ }^{25}$

White narra este ponto crítico por meio de dois líderes algonquinos, da tribo shawnee, Tecumseh e seu irmão Tenskwatawa. Suas ações foram uma última, e desesperada, tentativa de salvar o middle ground da dissolução. Quando Tecumseh conclamou seus patrícios às armas, em 1812, foi para tentar forçar os norte-americanos em direção a uma aliança. No entanto, como demonstra White (1991, p.516-517), esmagados entre uma potência expansionista, os Estados Unidos, e outra preocupada em defender suas colônias restantes na América do Norte, a Inglaterra, não restavam muitas escolhas para os algonquinos. Castigados pelas constantes guerras, por doenças e pelo crescente aumento populacional dos colonos brancos, os nativos já não eram uma força política que pudesse se contrapor aos impérios e tirar proveito de ambos.

Segundo White (1991, p. 520), Tecumseh é um personagem deveras interessante, porque sua história, simbolicamente, marca o surgimento histórico do índio como o Outro. Logo após a guerra, e durante todo o século XIX, ele foi representando como possuindo características brancas, mas elas 
Rememorando os Filhos de Onontio: Richard White, The Middle Ground e a escrita da história da América do Norte colonial

eram utilizadas somente para demarcar sua diferença em relação aos euro-americanos. Ele era um homem honrado, inteligente e excelente estrategista militar. Seu “instinto", entretanto, o impelia a não abandonar a selvageria e a cultivar um modo de vida fadado ao desaparecimento. Ele era, assim, o símbolo de um paradoxo: suas melhores características eram transformadas em exceções dentro do universo nativo (elas eram “brancas”), apesar de ele ser, em última instância, um “bárbaro”. A sua história, como narrada pelas gerações subsequentes de norte-americanos, reunia as duas políticas perniciosas referidas por White, já que o assimilavam-no ao universo europeu apenas para demonstrar a irreversibilidade do processo de extermínio ${ }^{26}$ (SLOTKIN, 1973, p. 427-430).

White (1991, p. 521) reverte este processo, a partir do uso de alguns textos fragmentários produzidos pelos próprios índios sobre Tecumseh. ${ }^{27}$ Neles, o líder aparecia como um “filho” abandonado pelo "pai” inglês na luta contra os norte-americanos, mas sancionado por um “espírito divino” para tentar unir os algonquinos uma vez mais, não para resistirem até a morte contra o avanço da nova nação, mas para tentar encontrar a possibilidade de reconciliação entre estes “irmãos” desgarrados (WHITE, 1991, p.518-520). A linguagem, embora bastante simbólica, remete diretamente aos termos pelos quais os algonquinos entendiam o middle ground: eles e os americanos brancos eram filhos de um mesmo genitor, a Inglaterra, e, portanto, não poderia haver confronto entre eles. Era preciso, assim, reformar a aliança e restabelecer o terreno comum entre ambos. Tecumseh, sob esta perspectiva, não é o Outro, insondável e destinado à barbárie, mas um homem engajado na reconstrução de um universo que estava ruindo diante da violência e da falta de compreensão mútua (WHITE, 1991, p.521). Neste caso, o Outro é a República norte-americana: é ela que invade o middle ground, devasta as experiências comuns e o espaço de coexistência que, durante quase duzentos anos, alimentou a relação entre nativos e colonos. Com isso, White imputa o fim de uma sociedade que, se não era perfeita, era uma resposta bastante inteligente para os problemas que afligiam brancos e índios durante o período colonial, à intolerância e a má-vontade dos norte-americanos em tentar entender como funcionava o middle ground.

Estas fontes também revelam algumas tentativas dos algonquinos de registrar uma parcela de sua história e de garantir o respeito a alguns acordos firmados. Embora calcadas na lógica do middle ground, com o uso de citações bíblicas entremeadas com mitos autóctones, elas representaram a busca por um sentido de fixidez, como se a escrita pudesse salvar seu mundo da dissolução. Tenskwatawa narra as aventuras de seu irmão para salvá-las do esquecimento e para assegurar que a voz indígena pudesse ser ouvida, e compreendida, pelas futuras gerações. Isto, no entanto, chocou-se diretamente com a construção do índio como o Outro e com seu surgimento como algo a ser estudado, uma relíquia de um tempo fora da História. Neste caso, na narrativa, o 
irmão de Tecumseh serve como uma sinédoque dos indígenas e sua história é paradigmática no que tange à dissolução do middle ground: “[...] once Tenskwatawa had been a human being whom whites had spoken to, listened to, argued with and feared. He was now but an object of study" 28 (WHITE, 1991, p.523). Outrora ouvidos, temidos e respeitados, os nativos foram não só relegados à marginalização além do middle ground; foram também retirados de uma história da qual eram parte essencial.

\section{Middle ground, colonialidade e a América contemporânea}

Como qualquer narrativa histórica, The Middle Ground cria um passado a partir de um presente, projetando, assim, certas expectativas de futuro. Sobre isto, é possível concordar com Beverley Southgate (2006, p.55), quando ele afirma que os historiadores são os arquitetos e construtores de um passado que, sem eles, seria apenas uma pilha de escombros sem sentido. Os desígnios propostos pelas narrativas históricas podem, assim, propor futuros a serem realizados, a partir da narração de certas experiências passadas. Em outras palavras, se, obviamente, não podemos mudar o passado, podemos tentar mudar as consequências deste passado.

Isto é ainda mais candente no que tange às experiências de grupos marginalizados, cujas histórias não funcionam somente como uma forma de recuperação de um passado silenciado, mas como um instrumento para subscrever identidades presentes, sendo ferramentas políticas bastante importantes. Estas demandas de “voz e agência”, para citar Verónica Tozzi (2009, p.169), tornaramse ainda mais acentuadas numa conjuntura em que o conhecimento histórico fragmentou-se e os diversos grupos lutam para que suas histórias “verdadeiras” sejam contadas (TOZZI, 2005, p.139). Por isso mesmo, o historiador tem uma função social bastante acentuada: ao mesmo tempo em que não deve ceder às tentações fundacionistas de qualquer espécie, também deve, segundo Tozzi (2009, p.172), evitar perpetuar, com suas narrativas, as condições que causaram aquela primeira marginalização, por intermédio, por exemplo, da reificação de certas identidades ou da criação de histórias que pretensamente “encerram” determinadas questões e ajudam a silenciar demandas ainda pendentes. ${ }^{29}$

É justamente essa a crítica de White (1998, p. 230-231) à “política de vitimização” e à noção de “pureza cultural” indígena, que, segundo ele, acabam produzindo histórias que chancelam e legitimam uma visão passiva dos indígenas. No primeiro caso, sem, no entanto, nunca negar a violência da conquista e a brutalidade do regime de exploração social e esvaziamento cultural ao qual os nativos foram submetidos, White afirma: “[...] they are a people who are victimized, but 
Rememorando os Filhos de Onontio: Richard White, The Middle Ground e a escrita da história da América do Norte colonial

they are hardly simple victims. They partially shape their fate under conditions who are not of their choosing”30 (1998, p.234). Esta recusa de uma identidade contemporânea baseada somente na vitimização parece ser um dos âmbitos políticos mais pronunciados de The Middle Ground. Como ele próprio colocou em outro texto (WHITE, 1998, p. 235), as histórias que narram a conquista da América somente a partir do tropo do "genocídio" paradoxalmente reforçam a ideia dos nativos como o Outro e como seres incluídos à força, por assim dizer, na História. Que os nativos foram massacrados, não restam dúvidas; que eles sobreviveram, também não.

Esta sobrevivência não foi, entretanto, apartada de processos sociais e culturais mais amplos. A defesa de uma "pureza cultural” indígena, como se, para eles, o processo histórico estivesse congelado, serve a mesma perniciosa função política das narrativas de vitimização: “[...] the book assumes that people are not necessarily stupid, simple, or parochial; contact situations created not only violence, xenophobia, but also new cultural formations and new understandings” 31 (WHITE, 2006, p. 11). A obsessão com “pureza cultural” só serve, deste modo, para perpetuar a ideia de um “outro” incapaz não só de ser assimilado, mas de ser entendido, negando, deste modo, a capacidade humana de se estabelecer canais de comunicação entre grupos diferentes. "Vitimização” e “pureza cultural” são, portanto, as duas faces de uma mesma nefasta moeda.

Por outro lado, The Middle Ground também parece movido por um intenso desejo de justiça. Se esta não pode ser dada no plano jurídico, parece ser obrigação do historiador fornecê-la no plano discursivo, acalmando os mortos que não podem mais falar, para citar Certeau (2002, p. 14), e estabelecendo uma comunicação destes com os vivos. Ao recuperar sua ação na sociedade colonial, retirando-lhes tanto o status de Outro, fosse ele o "selvagem” ou o nobre “Adão americano”, ele pôde resgatar a humanidade destes homens e mulheres, dando-lhes o papel que por tanto tempo lhes havia sido negado: a restauração da complexidade deste quadro histórico é também a documentação da agressão explicita por meio da qual os índios foram forçados para fora do middle ground e marginalizados como parte de um contrato social que dificilmente teriam escolhido (KEARNS, 1998, p. 396).

A restauração do Outro funciona como um modo de aceitar a alteridade e alcançar uma acomodação mutuamente compreensível entre seres humanos com estilos de vida e visões de mundo diferentes. Para um país conhecido pelos conflitos raciais, abertos ou velados, The Middle Ground pode ser entendido como um manifesto em prol de uma sociedade multicultural engajada em um constante diálogo sobre seu funcionamento e seus limites, mas também otimista quanto às possibilidades de compromisso entre seus integrantes ${ }^{32}$. Sobre isto, afirmou Kearns: 
The story of how Native American society was underdeveloped, then, serves as an explicit rebuke to the supposed equality of all before the law. Nevertheless, White's studies also provide empirical grounds for maintaining that alternative arrangements are imaginable in the present. ${ }^{33}$ (KEANS, 1998, p.397).

Pode-se dizer, assim, que a preocupação de White (1998, p. 223) com um passado em constante reinvenção, um passado que se recusa a ser fechado de forma definitiva, abre espaço para aquela ética da operação historiográfica mencionada por Michel de Certeau (1987, p. 217). Este âmbito da historiografia define, segundo o jesuíta francês, a distância entre aquilo que é e aquilo que deve ser, e este distanciamento designa um espaço onde temos algo a fazer. Este "algo a fazer”, no caso de The Middle Ground, é a recuperação de vozes e histórias silenciadas e o reconhecimento de que nem todos os caminhos que se ofereciam aos filhos de Onontio presumiam sua aniquilação e sua assimilação, abrindo, deste modo, um horizonte renovado de diálogo entre grupos aparentemente antagônicos. A consequência disto é uma narrativa que reconhece que a história não é algo inescapável e que os seres humanos, em seus diversos e conturbados presentes, têm ao seu dispor diversos futuros em aberto, dependentes das escolhas possíveis em diferentes tempos históricos.

Ademais, como o próprio White (2006, p. 10) resaltou recentemente, é impossível contar a história da modernidade sem levar em conta seu "outro”, a colonialidade: “[...] marking Indian peoples a people of tradition, outside the realm of the modern, as if they had no role in forging modernity and as if their history had no part in it” ${ }^{34}$. Seguindo este raciocínio, é possível ancorar as preocupações de White às de Walter Mignolo (2001; 2005), que assevera que a restituição da historicidade dos subalternos ajuda a compreender a forja da modernidade como algo global, e não como um processo meramente europeu ou, no caso da América do Norte, euro-americano. Esta narração da modernidade como sendo inexoravelmente ligada à colonialidade permitiria, segundo Mignolo (2001, p.17-19), o resgate de uma profusão de "histórias locais” silenciadas por um “desígnio global” e a reescrita da história da modernidade a partir do ponto de vista daqueles maculados pela “ferida colonial” 35 e tornados subalternos neste processo.

O livro de White, neste sentido, cumpre este papel em dois âmbitos: em primeiro lugar, ao narrar a própria história do middle ground, e, ao fazê-lo, demonstrar como historicamente surgiu este “Outro”. Se num primeiro momento, indígenas e europeus eram o “Outro” uns dos outros, em fins do século XVIII, o diálogo possível entre os dois grupos foi encerrado. Os segundos recusaramse a escutar as vozes indígenas, ou, se as ouviram, recusaram-se a compreendê-las, como haviam feito durante mais de dois séculos no pays d'en haut. É esta naturalização do indígena como “indomável”, como “selvagem” e como “bárbaro” que forneceu, portanto, a justificativa moral para 
Rememorando os Filhos de Onontio: Richard White, The Middle Ground e a escrita da história da América do Norte colonial

sua assimilação ou seu extermínio. Isto nos ajuda a entender aquela transformação de diferenças em valores e na criação da “diferença colonial” (MIGNOLO, 2001, p.13).

A lógica do middle ground havia operado com base na construção de valores comuns por meio da constatação de diferenças, que não foram consideradas necessariamente intransponíveis por aqueles agentes históricos. No crepúsculo do século XVIII, contudo, estas divergências tornaramse, no discurso dos colonizadores, barreiras naturais ao mútuo entendimento entre brancos e nativos. Com a construção destes obstáculos, reificou-se a dominação colonial como natural. Como dito antes, começava aqui a triste história de remoções forçadas, do assimilacionismo radical, dos tratados rompidos e da subalternização dos nativos. A recuperação de uma das peças desta história, por parte de White, ajuda, portanto, a compreender este processo de subalternização das sociedades nativas da América do Norte.

\section{Notas}

${ }^{1} \mathrm{O}$ termo “middle ground” é de difícil tradução, na medida em que aponta tanto para uma espacialidade, “o território intermediário”, quanto para uma condição mais geral, “o meio-termo” entre partes conflitantes. Como White parece têlo usado-o em ambos os sentidos, optamos por não traduzi-lo para o português.

${ }^{2}$ A lista de livros inspirados, de forma laudatória ou crítica, por The Middle Ground é imensa e escapa, em muito, os limites de uma simples nota explicativa. Para um panorama bastante completo do impacto do livro de White, tanto nos Estados Unidos, quanto no Canadá, ver DESBARATS, 2006.

${ }^{3}$ Apesar de sua importância na historiografia norte-americana, The Middle Ground continua, infelizmente, sem tradução para a língua portuguesa.

${ }^{4}$ Gostaríamos de deixar claro que White não foi o único autor responsável por esta reescrita da história da América do Norte colonial e nem foi o primeiro a chamar a atenção para a "agency” dos sujeitos subalternos. Como colocaram Ellen Fitzpartick (2002) e Peter Novick (1988), a reescrita do passado norte-americano, a partir de uma perspectiva “subalterna”, começa ainda nos anos 1970, atingindo sua maturação nos anos 1980 e 1990. Neste sentido, The Middle Ground deve ser entendido como fazendo parte desta conjuntura disciplinar mais ampla.

${ }^{5}$ White também é um respeitado autor de História Ambiental. No entanto, dada a complexidade de sua profunda ligação com este campo, não teceremos maiores análises sobre esta parte especifica de sua obra, já que o tema daria, por si só, material para outro texto.

6 "O colapso de seus sistemas de subsistência e sua integração com os mercados mundiais trouxe uma crescente dependência em relação ao núcleo capitalista, falta de escolha econômica e profundas mudanças sociais e políticas nestas sociedade”.

${ }^{7}$ Entre os pontos da plataforma do Movimento do Índio Americano, fundado em 1968, estavam a revisão de todos os tratados realizados entre o governo norte-americano e as tribos, a melhoria das condições de vida nas reservas, devolução de antigas terras comunitárias e campos de caça, respeito aos costumes nativos e a dissolução do Departamento de Assuntos Indígenas. Alguns setores mais radicais defendiam um rompimento violento com os Estados Unidos como forma de retorno à soberania das nações indígenas. O ato mais famoso do MIA foi a tomada do Departamento de Assuntos Indígenas, em Washington, no ano de 1972.

${ }^{8}$ Além disso, segundo David Lewis (1996, p. 230) e Kelly Chaves (2008, p. 489), a contribuição também se deu no campo teórico-metodológico, com a adoção da chamada "etno-história", que empregava uma combinação de métodos históricos e antropológicos para o estudo das sociedades nativas. Segundo estes autores, a ampliação da noção de documento histórico por parte dos etno-historiadores, com a incorporação de registros orais e arqueológicos, por exemplo, ao rol de fontes primárias legítimas, acabou-se se estendendo para outros campos e hoje fazem parte do repertório intelectual de toda a profissão.

${ }^{9}$ As principais características da NWH eram a rejeição da frontier thesis, a abordagem "regionalista” para a história do Oeste, a incorporação de outros atores sociais negligenciados pelos turnerianos (indígenas, negros, mulheres, operários, imigrantes pobres, etc.) e a adoção uma perspectiva trágica ou irônica para a história norte-americana, enfatizando tanto 
seus sucessos, quanto seus fracassos. Sobre os debates intensos que sacudiram o campo da Western History nas décadas de 1980 e 1990, ver AVILA, 2010.

10 “A história das relações entre brancos e indígenas não produziu narrativas complexas”.

11 “O encontro entre o mar e o continente, como o encontro de indígenas e brancos, tanto cria, quanto destrói. O contato não era uma batalha entre forças primais, onde somente uma poderia sobreviver. Algo novo podia surgir”.

${ }^{12}$ Da mesma maneira, não servia uma história centrada no espaço do estado-nação, naturalizado e estendido até o período colonial. Por isso mesmo, utilizamos a expressão “América do Norte” para designar o marco territorial da narrativa de White, já que os Grandes Lagos eram uma região em constante disputa, tanto entre impérios coloniais (franceses e ingleses) e nativos, quanto, em fins do séc. XVIII, entre um estado-nação independente, um império colonial e grupos indígenas.

${ }^{13}$ Este era o nome dado pelos franceses, no período colonial, à delimitada a Leste pelo rio Ohio e pelo Lago Ontario, seguindo ao norte até as terras ao norte do Lago Superior, descendo pelo rio Mississipi, a oeste, até ao rio Missouri, ao sul. Sua fronteira setentrional era o encontro deste curso d'água com o Ohio. Atualmente, o pays d'en haut corresponde à boa parte do Meio-Oeste norte-americano e ao Centro-Sul do Canadá.

${ }^{14}$ White (1991, p. ix) usa este termo, que tem uma conotação étnica e linguística bem específica, para significar mais do que uma simples origem genética ou uma língua compartilhada por todos estes nativos. Segundo o historiador, os algonquinos incorporaram outras etnias em seu seio, principalmente entre aquelas tribos que fugiam do litoral da Nova Inglaterra e encontravam abrigo em suas aldeias. Neste sentido, a região dos Grandes Lagos, sob domínio francês, era um amálgama de etnias diferentes, mas que, sob a liderança algonquina, acabavam compartilhando uma cultura mais ou menos comum e distinta da de outros nativos (como os iroqueses a leste e os sioux a oeste, por exemplo). Do mesmo modo, eles também derivavam sua identidade do fato de serem aliados dos franceses em suas lutas imperiais contra os britânicos, sendo conhecidos como "Filhos de Onontio" (nome honorífico dado pelos indígenas aos diversos governadores coloniais do Canadá) e amplamente recompensados por isto.

15 “O lugar entre culturas, povos e entre impérios e o mundo sem Estado das aldeias. É um lugar onde viviam muitos dos súditos norte-americanos e aliados dos impérios. É a área entre o contexto histórico da invasão e ocupação européia e o contexto da derrota e recuo indígena”.

16 "Eu fui bem específico sobre os elementos necessários para a construção de um espaço de um frágil equilíbrio de poder, necessidade mútua ou o desejo pelo o que o outro possuía, e uma inabilidade de cada um dos lados em arregimentar força suficiente para compelir o outro a mudar. Força e violência não são estranhas ao processo de criação e manutenção de um middle-ground, mas o elemento crítico é a mediação”.

17 "O middle ground cresceu de acordo com a necessidade das pessoas de encontrar um meio, que não a força, para ganhar a cooperação ou o consentimento de estrangeiros. Para serem bem-sucedidos, aqueles que operavam no middleground tinham necessariamente que tentar entender o mundo e o raciocínio de outros e assimilar suficientemente este raciocínio para seus próprios propósitos”.

${ }^{18}$ Apesar de uma aparente unidade entre os algonquinos, o pays d'en haut era repleto de rivalidades intertribais que, não raro, resultavam em conflitos fatais entre os grupos rivais. Neste sentido, o governador colonial operava como um "pai” resolvendo as querelas entre seus "filhos". Esta afirmação do caráter paternal da aliança, que pode parecer extremamente eurocêntrica para alguns, era, na verdade, a compreensão indígena dos laços que os uniam aos franceses. Aqui, quem fala não são apenas os europeus, mas os próprios nativos - são suas falas que desvelam sua condição como "filhos de Onontio" e não as dos administradores coloniais. Ver, por exemplo, os discursos do chefe algonquino Le Pesant diante dos franceses, em que ele se dirige aos brancos como "pais”, ao pedir a mediação do governador para a solução de escaramuça entre comerciantes de pele franceses e jovens guerreiros das tribos ottawa (WHITE, 1991, p. 8290).

${ }^{19}$ Por causa disto, a união entre algonquinos e franceses manteve-se extremamente tensa durante todo o período, já que os chefes indígenas não possuíam poder suficiente para manter os descontentes, geralmente jovens guerreiros, sob controle e submissos aos seus desejos. Nos 150 anos de duração da aliança franco-algonquina, não foram poucas as escaramuças entre franceses e nativos, o que forçava seus líderes a uma constante negociação, na lógica do middle ground. Do mesmo modo, existiam profundas fissuras internas naquela sociedade indígena, especialmente entre tribos rivais, o que também demandava a permanente mediação de Onontio.

${ }^{20}$ White (1998, p. 220-224) é extremamente crítico daqueles autores que, com o intuito de defender as sociedades e culturas nativas, adotam uma postura "anti-historicizante", enfatizando o caráter "tradicional” destas sociedades, em oposição às tendências "historicistas” da cultura ocidental, consideradas “colonialistas” e “imperialistas” - posição defendida por autores ligados ao próprio movimento indígena, como Calvin Martin. Segundo ele, estas visões reforçam a ideia de que os nativos estão “fora da história” e, paradoxalmente, reforçam sua passividade diante dos brancos.

${ }^{21}$ O Canadá, incluindo todo o pays d'en haut, foi cedido à Inglaterra em 1763, após a derrota da França na Guerra dos Sete Anos, na Europa. A Rebelião de Pontiac (1763-1766) foi uma reação dos nativos à cessão, e mesmo não sendo, necessariamente, um levante para reinstaurar Onontio, ela obteve o apoio militar de uma parcela da população francocanadense, receosa pela perda de seus direitos. Em 1851, Francis Parkman, eminente historiador amador da fronteira, escreveu o livro The Conspiracy of Pontiac (“A Conspiração de Pontiac”), em que o líder algonquino era retratado 
como um "nobre selvagem”, embora violento e profundamente racista em relação aos europeus, dedicado a reconquistar as terras perdidas para os brancos, mas irremediavelmente fadado ao fracasso. Ver ETULAIN, Richard, 1996, p. 33-35.

${ }^{22}$ Os ingleses possuíam uma política indígena bem mais agressiva do que os franceses, demandando a submissão completa dos nativos aos interesses de seu império. Um dos elementos que contribuía para isto era a grande diferença populacional entre as suas colônias norte-americanas e aquelas da França: enquanto nesta última existia uma falta crônica de soldados e colonos, nas primeiras existia uma pressão constante por novas terras, para atender as demandas de uma população cada vez maior (existia um milhão de pessoas nas Treze Colônias quando da cessão do Canadá, contra os sessenta e cinco mil franceses do Quebec). Neste sentido, as autoridades coloniais não desejavam a construção da middle ground, mas a destruição dele (WHITE, 1991, p. 223-268).

${ }^{23}$ A documentação sobre Pontiac utilizada por White é uma mistura de documentos oficiais, diários de soldados e oficiais ingleses envolvidos na disputa, transcrições de encontros diplomáticos entre britânicos e nativos, relatos de viajantes e documentação produzida por jesuítas, mestiços e índios das missões francesas no pays d'en haut.

24 Jefferson defendia a colonização de todo o Oeste norte-americano com pequenos fazendeiros. Para ele, os nativos deviam ser assimilados e ensinados a trabalhar na terra como os europeus, abandonando a caça e o nomadismo em prol da civilização. Caso não o fizessem, seriam derrotados pelo ritmo indelével do progresso. SLOTKIN, 1973, p. 245-247.

25 “Os norte-americanos inventaram os índios e os forçaram a viver com esta invenção. [...]. Desde então, temos visto a história do período colonial ou do começo da República através desde prisma do 'outro' ”.

${ }^{26}$ Ironicamente, um dos principais nomes das guerras contra os indígenas no século XIX, William Tecumseh Sherman, foi batizado em homenagem ao líder shawnee.

${ }^{27}$ Ele usa a transcrição de duas lendas indígenas contadas por Tenskwatawa. Restam dúvidas, entretanto, se foi o próprio irmão de Tecumseh (não se sabe se ele era letrado) que as registrou ou se foi algum outro nativo, ligado a ele.

28 “Outrora, Tenskwatawa fora um ser humano com o qual os brancos conversaram, ouviram, discutiram e temeram. Agora ele era um objeto de estudo".

${ }^{29}$ De acordo com Tozzi (2009, p. 124-126), qualquer tentativa de se encerrar uma discussão historiográfica com apelos a uma "verdade definitiva” ameaça replicar as condições que criaram aquela marginalização primeira. Por isso mesmo, a atividade historiográfica deve ser sempre pautada pelo debate contínuo e pela abertura a leituras e releituras do passado, não importa o quão radical possam parecer a uma primeira vista.

30 "Eles são um povo que é vitimizado, mas não são simples vítimas. Eles parcialmente moldam seu destino sob condições que não são de sua escolha”.

31 “As pessoas não são necessariamente estúpidas, simples ou provincianas; situações de contato não criaram somente violência e xenofobia, mas novas formações culturais e entendimentos”.

${ }^{32}$ Em um texto publicado em 2006, White (2006, p. 13-14) ancorou a inspiração para The Middle Ground nestes termos: "[...] the larger problem that inspired The Middle Ground, and which continues to fascinate me, is how, when historically and in modern society people get so much wrong, does the world still manage after a fashion to work?” .

33 “A história de como a sociedade dos nativos da América foi subdesenvolvida serve, então, como uma refutação explícita da suposta igualdade de todos perante a lei. Ainda assim, os estudos de White fornecem bases empíricas para a crença de que arranjos alternativos são imagináveis no presente”.

34 “Marcando os povos indígenas como 'um povo de tradição', fora do reino do moderno, como se eles não tivessem tido nenhum papel na forja da modernidade e como se sua história não tivesse parte nisto”.

${ }^{35}$ Segundo Mignolo (2005, p. xii), a "ferida colonial” é o "sentimento de inferioridade imposto a seres humanos que não se enquadram no modelo predeterminado da narrativa da modernidade”.

\section{Referências}

AVILA, Arthur Lima de. Território Contestado: a reescrita da história do Oeste norte-americano (c. 1985- c. 1995). Tese de Doutorado em História, UFRGS. Porto Alegre, 2010.

BARKSDALE, K. The Boundaries Between Us: Native and Newcomers along the Frontier of the Old Northwest Territory, 1750-1850. West Virginia History. Morgantown: Eberly College Press, Spring, 2007, vol. 1, n. 1, p. 95-96.

BARR, D. (org.). The Boundaries Between Us: natives and newcomers along the frontiers of the Old Northwest Territory, 1750-1850. 1 ed. Kent: Kent State University Press, 2006. 
BERKHOFER, Jr.; ROBERT F. The Political Context of the New Indian History. The Pacific Historical Review. Berkeley: The University of California Press, Nov. 1971, vol. 40, n. 3, p. 357382.

BERKHOFER, Jr.; ROBERT F. Review of The Middle Ground. The Journal of American History. Bloomington: Organization of American Historians, Dec. 1992, vol. 79, n. 3, p. 1134-1135. .

CALLOWAY, C. G. Native American History and the Search for Common Ground. Reviews in American History. Baltimore: The Johns Hopkins University Press, Dec., 1992, vol. 20, n. 4, p. 447-452.

CERTEAU. M.. Heterologies: discourses on the Other. Minneapolis: University of Minnesota Press, 1987.

CERTEAU, M. A Escrita da História. Rio de Janeiro: Forense Universitária, 2002.

CHAVES, K. M. Ethnohistory: from inception to postmodernism and beyond. The Historian. Cambridge: Blackwell Publishing, Sep. 2008, vol. 70, n. 3, p. 486-516.

DELORIA, P. J. What is the Middle Ground, Anyway? The William and Mary Quarterly. Williamsburg: The College of Will and Mary, Jan. 2006, 3d series, vol. LXIII, n. 1, p. 15-22..

DESBARATS, C. Following the Middle Ground. The William and Mary Quarterly. Williamsburg: The College of Will and Mary 3d series, vol. LXIII, n. 1. Jan. 2006. p. 9-14. p. 81-97.

DUVAL, K. The Native Ground: Indians and Colonists in the Heart of the Continent. 1 ed. Philadelphia: University of Pennsylvania Press, 2004.

EDMUNDS, R. D. Native Americans, New Voices: American Indian History, 1895-1995. The American Historical Review. Washington: American Historical Association, Jun, 1995, vol. 100, n. 3, p. 717-740.

EDMUNDS, R. D. Blazing New Trails or Burning Bridges: Native American history comes of age. The Western Historical Quarterly. Salt Lake City: The University of Utah Press, Spring, 2008, vol. 39, n. 1, p. 5-15.

ETULAIN, R. Reimagining the Modern American West: a century of fiction, history and art. 1 ed. Tucson: University of Arizona Press, 1996.

FITZPATRICK, E. History’s Memory: writing America’s past, 1880-1980. Cambridge: Harvard University Press, 2002.

GUIMARÃES, M. L. S. Entre as Luzes e o Romantismo: as tensões da escrita da história no Brasil oitocentista. In: GUIMARÃES, M. L. S. (org.). Estudos sobre a Escrita da História. Rio de Janeiro: Sete Letras, 2007.

HAGAN, W. T. The New Indian History. In: FIXICO, Donald L. (org.). Rethinking American Indian History. 1 ed. Albuquerque: The University of New Mexico Press, 1997. p. 27-42.

KEARNS, G. The Virtuous Circle of Facts and Values in the New Western History. Annals of the Association of American Geographers. Washington: AAG, Sep.1998, vol. 88, n. 3. p. 377-409. 
Rememorando os Filhos de Onontio: Richard White, The Middle Ground e a escrita da história da América do Norte colonial

KLEIN, K. L. Frontiers of Historical Imagination: narrating the European conquest of NativeAmerica, 1890-1990. 1 ed. Berkeley: University of California Press, 1997.

LEWIS, D. R. Still Native: the significance of Native Americans in the history of the $20^{\text {th }}$ century American West. In: MILNER, Clyde A. (org.). A New Significance: re-envisioning the history of the American West. Oxford: Oxford University Press, 1996. p. 213-240.

MANCALL, P. C. Review of “The Middle Ground”. The American Historical Review. Washington: American Historical Association. Dec. 1992, vol. 97, n. 5, p. 1587-1588.

MIGNOLO, W. D. Local Histories/Global Designs: coloniality, subaltern knowledges and border thinking. 1 ed. Princeton: Princeton University Press, 2001.

MIGNOLO, W. D. The Idea of Latin America. 1 ed. Oxford: Blackwell, 2005.

MILNER II, C. A. et alli. A Historian who has Changed our Thinking: a roundtable on Richard White. The Western Historical Quarterly. Salt Lake City: The University of Utah Press, Sum. 2002, vol. 33, n. 2, p. 137-157.

NOVICK, P. That Noble Dream: the “Objectivity Question” and the American historical profession. Cambridge: University of Harvard Press, 1988.

SLOTKIN, R. Regeneration through Violence: the mythology of the American frontier, 1600-1860. 3 ed. Middletown: Wesleyan University Press, 1973.

SOUTHGATE, B. A pair of white gloves: historians and ethics. In: Rethinking History. London: Routledge Group, Mar. 2006, vol. 10, n. 1, p. 49-61..

TAYLOR, A. The Divided Ground: Indians, settlers, and the Northern Borderlands of the American Revolution. 1 ed. New York: Vintage Books, 2006.

THORNTON, R. Institutional and Intellectual Histories of Native American Studies. In: THORNTON, R. (org.). Studying Native America: problems and prospects. 1 ed. Madison: University of Wisconsin Press, 1998. p. 79-109.

TOZZI, V. El "Privilegio" de la Postergación: dilemas en las nuevas historiografías de la identidad. Analisis Filosófico. Buenos Aires: Sadaf, Nov. 2005, vol. 25, n. 2. p. 139-163.

TOZZI, V. La Historia Segun la Nueva Filosofia de la Historia. 1 ed. Buenos Aires: Prometeo Libros, 2009.

TURNER, F. J. The Frontier in American History. 20 ed. New York: Dove, 1996.

WEINSTEIN, B. História Sem Causa? A nova história cultural, a grande narrativa e o dilema póscolonial. In: História (São Paulo), Franca: Unesp, 2003, vol. 22, n. 2, p. 185-210.

WHITE, R. The Winning of the West: the expansion of the Teton Sioux during the Eighteenth and Nineteenth Century. The Journal of American History. Bloomington: Organization of American Historians, Sep. 1978 vol. 85, n. 2, p. 319-344. 
WHITE, R. Land Use, Environment and Social Change: the shaping of Island County. 1 ed. Seattle: The University of Washington Press, 1979.

WHITE, R. The Roots of Dependency: subsistence, environment and social change among the Choctaws, Pawnees and Navajos. 1 ed. Lincoln: University of Nebraska Press, 1983.

WHITE, R. Race Relations in the American West. American Quarterly. Baltimore: The Johns Hopkins University Press, 1986. vol. 38, n. 3., p. 396-416.

WHITE, R. Trashing the Trails. In: LIMERICK, Patricia Nelson; MILNER II, Clyde A. \& RANKIN, Charles E. (org.). Trails: toward a New Western History. 1 ed. Lawrence: University of Kansas Press, 1991. p. 26-39.

WHITE, R. The Middle Ground: Indians, Empires and Republics in the Great Lakes Region, 16501815. 9 ed. Cambridge: Cambridge University Press, 1991.

WHITE, R. Using the Past: History and Native American Studies. In: THORNTON, Russell (org.). Studying Native America: problems and prospects. 1 ed. Madison: University of Wisconsin Press, 1998. p. 217-246.

WHITE, R. Creative Misunderstandings and New Understandings. The William and Mary Quarterly. Williamsburg: The College of Will and Mary, 3d series, vol. LXIII, n. 1. January, 2006. p. 9-14.

Recebido em 14/12/2010

Aprovado em 27/05/2011 